A Multidisciplinary Publication of Centre for Research,

Maitreyi College, University of Delhi

April 2020, Volume 1, Issue 1

Original Research Article

\title{
Relationship between Molecular Structure and Relative Sweetness of Various Artificial Sweeteners
}

\author{
Haritma Chopra, Ritu Gaba*, Ankita Chaudhary, Meenakshi Chugh and Komal Rawat \\ Department of Chemistry, Maitreyi College, Chanakyapuri, New Delhi -110021 \\ *Correspondence: ritubagga26@yahoo.co.in
}

\begin{abstract}
In the present work, the relationship between the molecular properties and sweetness level of a number of artificial sweeteners like aspartame, neotame, saccharin, sucralose, cyclamate, xylitol and alitame was studied. The molecular structures of the artificial sweeteners were generated, optimized and their properties like electrostatic potential, dipole, heat of formation, HOMO (Highest Occupied Molecular Orbital) and LUMO (Lowest Unoccupied Molecular Orbital) were calculated using Argus lab. Further, identification of AH, B and X sites based on AH-B-X theory was done with the help of electrostatic potential mapping, HOMOs and LUMOs for a few artificial sweeteners. A comparison was done among the sweeteners between their relative sweetness values by considering their structures and the way in which sugars bond to receptor sites. An attempt was made to develop a relationship between the relative sweetness and molecular properties of the sweeteners.
\end{abstract}

Keywords: Artificial Sweeteners, Molecular properties, Argus Lab

\section{INTRODUCTION}

\subsection{Background}

In the era of growing population, rapidly developing technologies and changing lifestyles, the number of people falling prey to diseases and disorders is also increasing. Every second person is diagnosed with some disease or the other. The disease may be a chronic disease or an acute disease. Factors responsible for the prevalent conditions include pollution, bad eating habits, inclination towards junk food, lack of physical fitness, work pressure, stress, etc.

One such disease is diabetes which is caused due to high intake of sugar and foods rich in carbohydrates over a prolonged period. Diabetes occurs owing to, either the pancreas not synthesizing enough insulin or when the cells do not respond properly to the insulin produced in the body. 
Pancreas is a glandular organ which is a part of the digestive system. It secretes numerous digestive enzymes and hormones including insulin. Insulin is a hormone that controls the metabolism of fats, proteins and carbohydrates by facilitating the absorption of glucose from the blood which is further converted into glycogen (Masharani \& German, 2011).

Diabetes is often referred to as a lifestyle disease. This leads to an increase in blood glucose level. Patients suffering from diabetes are therefore advised to limit their intake of sugar and carbohydrates. If not so, they may expose themselves to serious diseases affecting heart and blood vessels. As an aid to keep the blood sugar levels stable, diabetic patients are advised to use artificial sweeteners. Artificial sweeteners are designed in labs, taste like sugar but have less calorie content. Nowadays, dieticians also recommend artificial sweeteners to regulate obesity.

\subsection{Artificial sweeteners}

Artificial sweeteners are sweetening agents that are chemically synthesized and have a sweet taste like sugar but contain relatively less calorie content (Table 1). Therefore, they can be used as sugar substitutes in food items, toothpastes, chewing gum and beverages.

Artificial sweeteners which are used widely in the food industry are aspartame, sucralose, cyclamate, neotame and saccharin (Mortensen, 2006). Also, natural sweetening agents like Stevia and monk fruit extract are used in place of sugar. Although artificial sweeteners are used extensively, the issues related to their health effects have always been controversial.

\subsubsection{Aspartame}

Aspartame is a non-saccharide artificial sweetener used in some foods and beverages. Its IUPAC name is methyl L- $\alpha$-aspartyl-L-phenylalaninate. It was discovered by James $\mathrm{M}$. Schlatter in1965. It is a methyl ester of the dipeptide of the amino acids L-aspartic acid and L-phenylalanine.

It may generate methanol by hydrolysis under strongly acidic or alkaline conditions. The peptide bonds are also hydrolyzed giving free amino acids under harsh conditions. Upon ingestion, it is rapidly metabolized into aspartic acid, phenylalanine and methanol in ratio of 4:5:1 by mass and further breakdown gives formaldehyde, formic acid along with other residual products (Glória, 2003). The ADI (Acceptable Daily Intake) value set by FDA (Food and Drug Administration) for aspartame is $50 \mathrm{mg} / \mathrm{kg}$ body weight.

\subsubsection{Saccharin}

Saccharin is also a non-saccharide artificial sweetener which is used as a sugar substitute in drinks, candies, cookies and medicines. But it also has a bitter aftertaste if used in high 
concentrations. The IUPAC name of saccharin is 1,1-dioxo-1,2-benzothiazol-3-one and it is also called as benzoic sulfimide. It was discovered by Constantin Fahlberg in 1879. It has a high shelf life as it does not react chemically with other food ingredients (Chattopadhyay et al., 2011). The ADI value, issued by FDA for saccharin, is $15 \mathrm{mg} / \mathrm{kg}$ body weight.

\subsubsection{Sucralose}

Sucralose is prepared by the chlorination of sucrose (Queneau et al., 2007). It is done by the selective chlorination of sucrose in a multistep reaction in which three of the hydroxyl groups of sucrose are replaced by chlorine atoms. It was discovered by scientists Tate and Lyle in 1976. The majority of ingested sucralose is not broken down by the body, so it is non caloric. It is stable under heat and over a wide range of $\mathrm{pH}$ conditions. It is used in canned fruits, candies, soft drinks and breakfast bars. The ADI value given by FDA is $5 \mathrm{mg} / \mathrm{kg}$ body weight.

\subsubsection{Xylitol}

Xylitol is a polyalcohol used as a sweetener. It is produced from xylan, a polymer, which is extracted from hardwoods or corncobs. Xylan is further hydrolysed into xylose and catalytic hydrogenation of xylose yields xylitol. Its IUPAC name is $(2 R, 3 R, 4 S)$-pentane-1,2,3,4,5pentol.

It is used in drugs or dietary supplements, confectionaries, toothpaste and chewing gum. Though, it is as sweet as sucrose, it does not influence blood sugar levels since it is slowly absorbed in the body. Also, it is a non-fermentable sugar so it can help in reducing tooth decay (Maguire \& Rugg-Gunn, 2003). However, no ADI value has been issued by FDA; it is recommended not to consume more than $50 \mathrm{~g}$ per day.

\subsubsection{Sodium cyclamate}

This artificial sweetener which was discovered by Michael Sveda in 1937, has gained approval as a sweetener in at least 130 countries. However, considering its potential side effects it is banned in the United States (Weihrauch \& Diehl, 2004). It is a salt of cyclohexanesulfamic acid. It has a relative sweetness of 30-50 with respect to table sugar. It is immutable under heat and is often used along with sachharin. Its ADI value has been suggested to be $11 \mathrm{mg} / \mathrm{kg}$ body weight.

\subsubsection{Neotame}

Neotame is almost 1000 times sweeter as compared to sucrose. It is moderately stable to heating and is highly potent, readily metabolized and doesn't get accumulated in the body. 
The products of metabolism include methanol and de-esterified neotame. Since, a very small quantity of neotame is used, so the amount of methanol produced is also very low (Corti, 1999). The ADI value issued by FDI for neotame is $0.3 \mathrm{mg} / \mathrm{kg}$ of body weight.

Table 1: Optimized structures of various artificial sweeteners

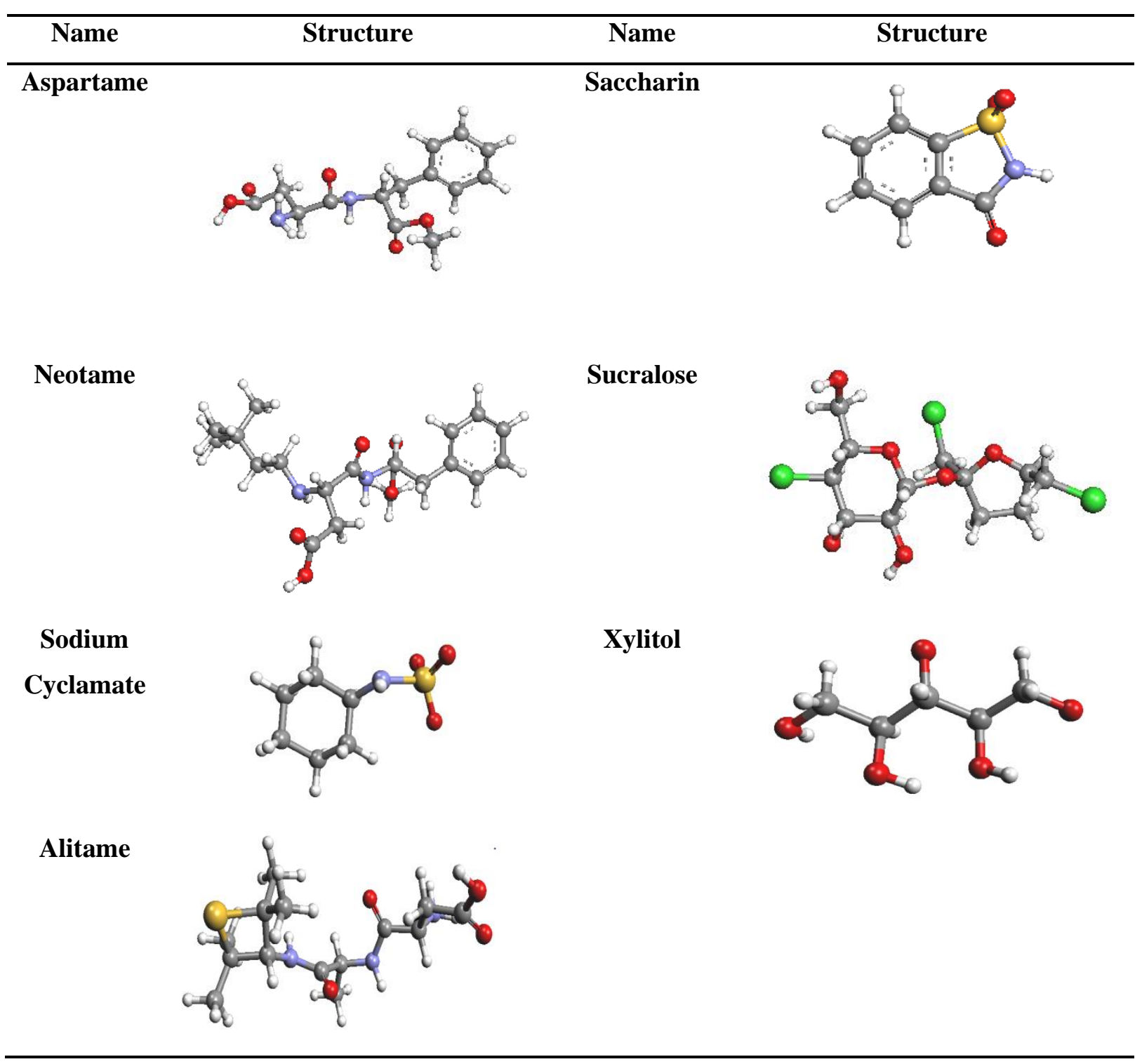

\subsubsection{Alitame}

Similar to aspartame, alitame also consists of aspartic acid. While it doesn't contain phenylalanine, as aspartame does, however, it consists of a dipeptide and is about 2000 times sweeter as compared to sugar (Walters et al., 1991). It is odorless and non-hygroscopic and is soluble in most polar solvents. It is quite stable at high temperatures and a wider $\mathrm{pH}$ range. 


\subsection{Computational approach}

Computational chemistry is a method of examining molecular properties like molecular geometry, energies of molecules, spectra, other physical properties and chemical problems on a computer. It can be used to model a molecular system even before synthesizing it in the laboratory or those which aren't easily available and are expensive to buy. It allows chemists to speculate before carrying out actual experiments and prepares them for making observations.

Computational chemistry employs various tools to carry out such determinations. One such tool is the Ab Initio method which involves the solving of the Schrödinger equation for a molecule and yields energy and a wave function. The wave function obtained can be further used to deduce other molecular properties of the molecule. However, the Schrödinger equation can't be solved completely for a molecule having more than one electrons due to inter-electronic repulsion.

To overcome this difficulty, we make use of another tool of computational chemistry known as Semi-empirical method. The Semi-empirical calculations also involve the solving of Schrodinger equation but instead of calculating certain complicated integrals, they are either approximated or completely omitted. Parameters are obtained to estimate the omitted values by fitting the results to experimental data, making the computation faster.

The methods of semiempirical calculations have been improved and have become more simplified and sophisticated over time. The earliest method used was the PARISERPARRPOPLE method which has evolved into the NDO (Neglect of Differential Overlap) method (Lewars, 2011). Different methods developed under the NDO method include:

\section{- CNDO (Complete Neglect of Differential Overlap) Method}

This is a general-geometry method, since it is not limited to planar $\pi$ systems. The calculations use a minimal valence basis set of Slater-type orbitals, using just the valence electrons and the conventional atomic orbitals of each atom.

\section{- INDO (Intermediate Neglect of Differential Overlap) Method}

It goes beyond CNDO by limiting the application of the ZDO approximation. Despite being more accurate than CNDO, it is nowadays mostly used for calculating UV spectra.

\section{- NDDO (Neglect of Diatomic Differential Overlap) Methods}

In this the ZDO approximation is not applied to orbitals on the same atom but is used only for atomic orbitals on different atoms. It is the basis of various currently used 
semiempirical methods developed by M.J.S. Dewar that include MNDO, AM1 and PM3 (Lewars, 2011).

In this paper, we have used computational approach to study the structure and properties of some of the artificial sweeteners. A lot of information such as molecular geometry, energy of the molecule, spectra etc. can be deduced without even actually synthesizing the molecule. It reduces the cost of experiment and increases the efficiency. Using computational chemistry, we have tried to establish a relationship between molecular structure and sweetness. On similar grounds, in future this approach can be extended to synthesise artificial sweeteners with considerable sweetness; thus, reducing their dosage. Since a number of artificial sweeteners have been linked with some side effects, these side effects can thus be minimised by reducing their dosage.

\section{MATERIALS AND METHODS}

Argus lab is a software, developed by Mark Thompson, based on quantum mechanics, it predicts the potential energies, molecular structures; geometry optimization of structure, vibration frequencies of coordinates of atoms, bond length, bond angle and reactions pathway (Gao \& Thompson, 1999). It can also be used to build HOMO, LUMO and electrostatic potential mapped surfaces.

Argus lab offers semi-empirical calculations for optimizing molecular structures. Though there are various calculation methods available like AM1, PM3, MNDO, ZINDO, we have used the PM3 method for the calculations as it gave best results for our study. The structures of the various artificial sweeteners were generated and optimized using Argus lab 4.0.1 (Table 1). Their molecular properties like heat of formation, dipole moment and single point energy (Table 3) were calculated and surfaces like HOMO, LUMO and electrostatic potential-mapped electron density (Table 2) were also generated.

HOMOs (Highest Occupied Molecular Orbitals) are the regions where there is high electron density with the highest energy. So, the electrophile must attack an atom on which HOMO is present. LUMOs (Lowest Unoccupied Molecular Orbitals) are the regions that accommodate any donated electrons in the lowest energy orbital. So, a nucleophile must attack an atom on which LUMO is present. Hence, the site of attack of electrophile and nucleophile on a particular molecule can be determined.

Electrostatic potential (ESP) is the potential energy experienced by a positive test charge at a particular point. If the ESP is negative then the region is of stability for a positive charge. If the ESP is positive then there is stability for a negative charge. Therefore, the site of attack of 
electrophile and nucleophile can be determined and the chemical reactivity of a molecule can be understood. The ESP was mapped on electron density surfaces.

\section{RESULTS}

Table 2: HOMOs and LUMOs of various artificial sweeteners as computed by Argus Lab 4.0.1

\begin{tabular}{ccc}
\hline Artificial & HOMO & LUMO \\
Sweetener & & \\
\hline
\end{tabular}

Aspartame
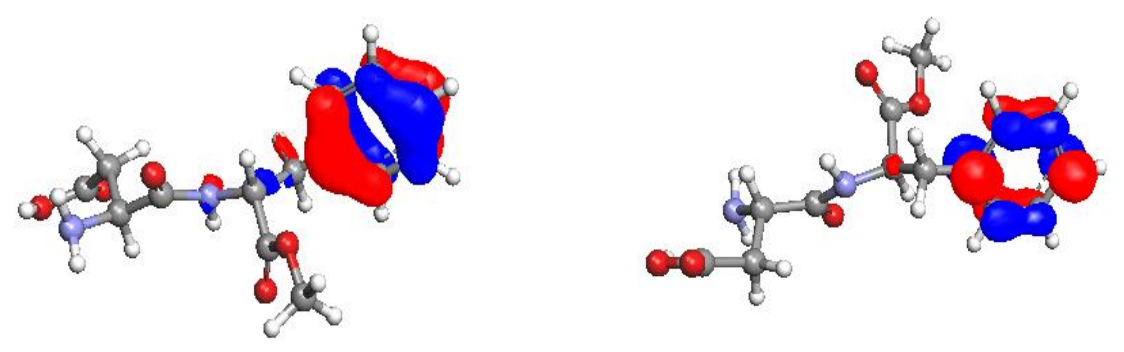

Saccharin
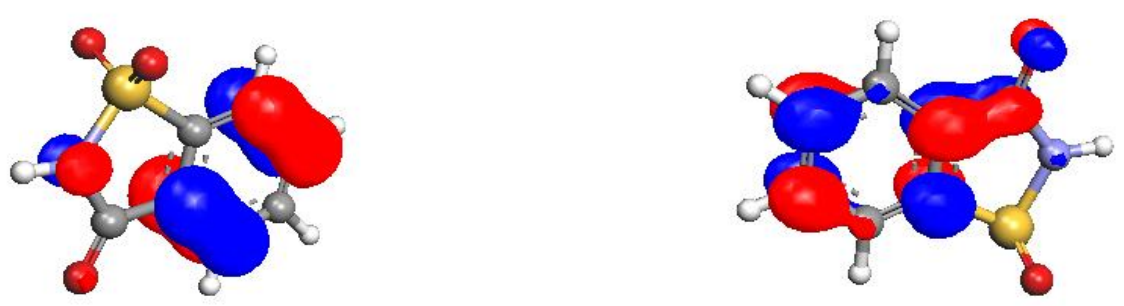

Sucralose
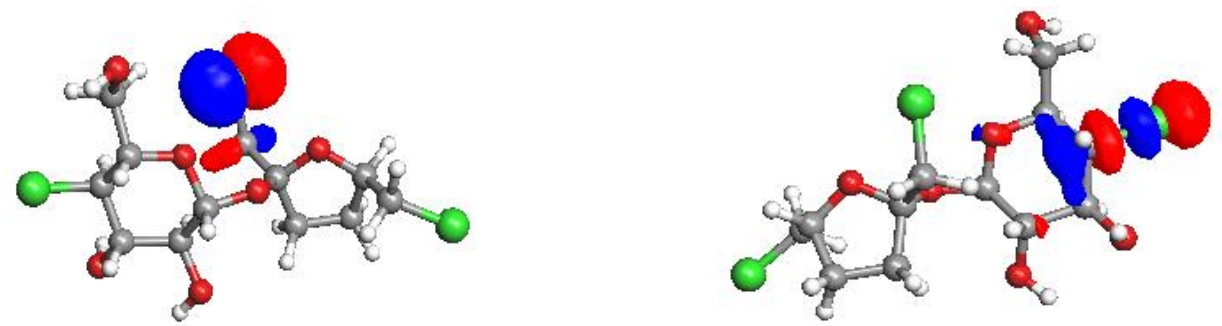
Neotame
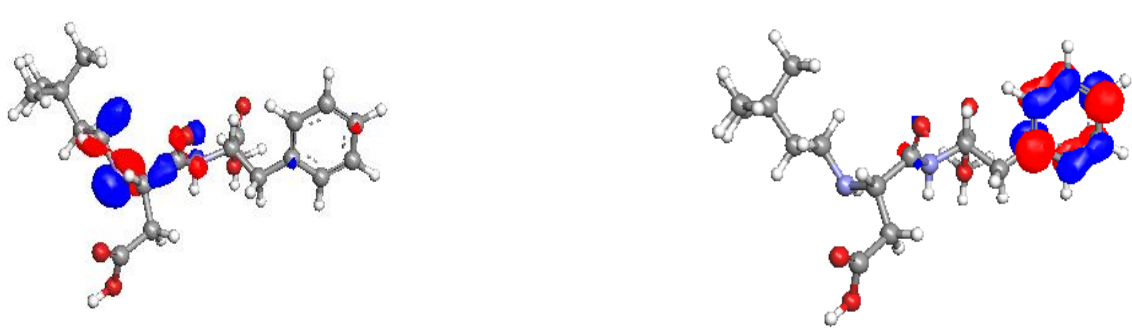

Cyclamate
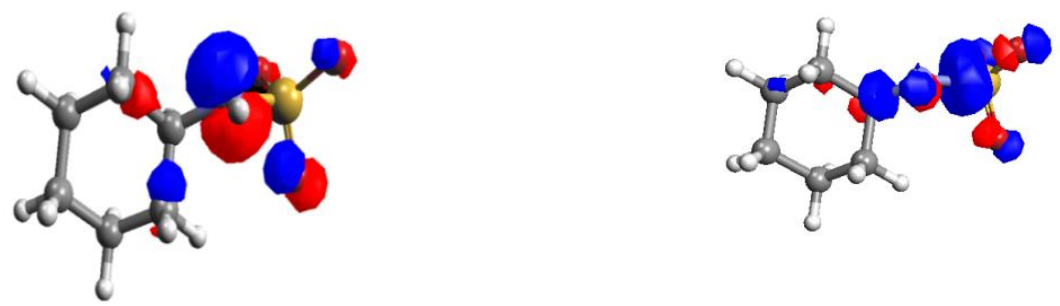

Xylitol
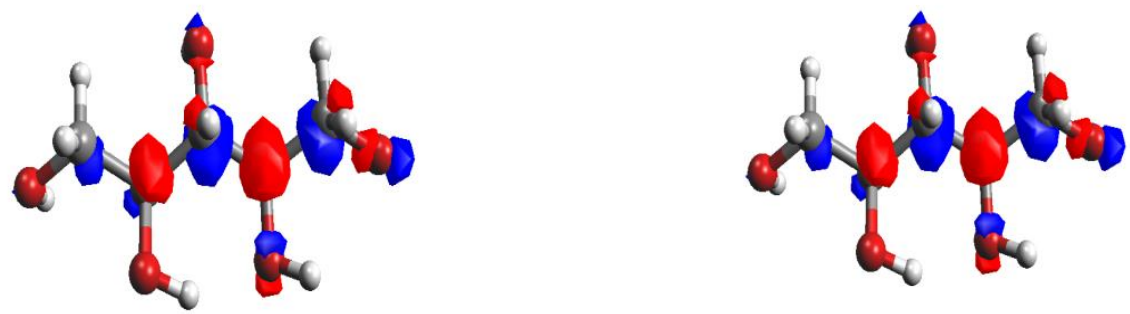

Alitame
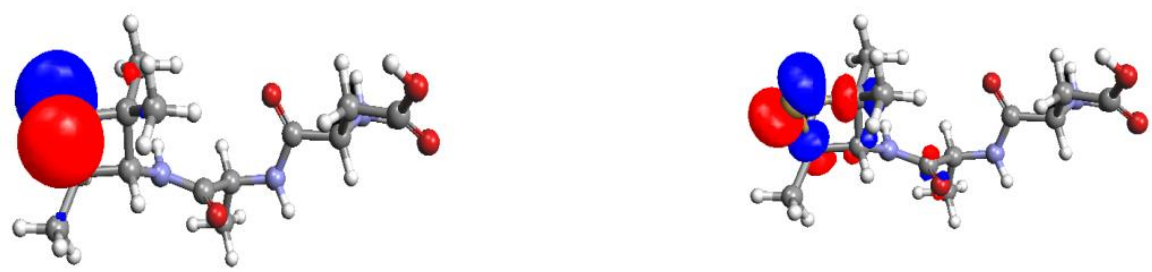

Sweetness is a potent psychobiological stimulus for many biological species, and particularly for humans of all ages. Sweetness clearly increases the palatability of numerous foods and beverages, and stimulates intake (Bellisle, 2015). It is perceived by the receptor proteins present in our taste buds. In mammals, it is the $G$ protein formed by the coupling of T1R3 protein and T1R2 protein which binds with the sweetening agent. Hence, the sweetener must have a proper molecular shape and electronic configuration in order to bind with the receptor. Also, it should be miscible in the chemical environment of the receptor (Guley \& Uhing). Georg Cohn in 1914 observed that multiple hydroxyl groups and $\mathrm{Cl}$ atoms are the characteristics of sweet molecules (Temussi, 2006). He also noticed that smaller weighing molecules were often sweeter than the larger ones. Another theory was proposed in 1919 by Oertly and Meyers which emphasised that for a compound to taste sweet it should contain 
one each of two classes of structural motif, a glucophore and an auxoglucs (Shapiro \& Grutlag, 2004).

$\mathrm{AH}-\mathrm{B}$ and $\mathrm{B}-\mathrm{X}$ theory are among the recent theories put forward to explain sweetness. $\mathrm{AH}-\mathrm{B}$ theory of sweetness was given by Rober Shallenberger and Terry Acree in 1963 (Acree et al., 1998). It states that in sweeteners there is an AH region which is usually an electronegative atom like $\mathrm{O}$ or $\mathrm{N}$ bonded to hydrogen and $\mathrm{B}$ region is a Lewis base. For a molecule to taste sweet, the distance between $\mathrm{AH}$ and $\mathrm{B}$ region should be between $2.4 \AA$ to $4 \AA$. A similar AHB unit is present in the receptor site through hydrogen bonding in a manner shown in Figure 1.

Table 3: Molecular properties of artificial sweeteners calculated using Argus lab 4.0.1

\begin{tabular}{lllllllc}
\hline \multirow{2}{*}{ Name } & $\begin{array}{l}\text { Heat of } \\
\text { formation }\end{array}$ & Final SCF & & \multicolumn{3}{c}{ Ground State Dipole (Debye) } & \multirow{2}{*}{$\begin{array}{l}\text { Relative } \\
\text { Sweetness }\end{array}$} \\
\cline { 5 - 7 } & $(\mathrm{kcal} / \mathrm{mol})$ & $(\mathrm{kcal} / \mathrm{mol})$ & $\mathbf{X}$ & $\mathbf{Y}$ & $\mathbf{Z}$ & Length & \\
\hline Aspartame & -186.8187 & -86007.3264 & 3.3428886 & 0.971982 & 2.537178 & 4.307775 & 180 \\
Sucralose & -267.0389 & -102098.2495 & -2.0438244 & -3.26356 & -2.94213 & 4.846045 & 600 \\
Saccharin & -63.2676 & -49221.9820 & -3.9070757 & -1.19605 & 0.029178 & 4.08615 & 400 \\
Cyclamate & -192.0825 & -49030.4042 & $-*$ & $-*$ & $-*$ & $-*$ & 30 \\
Xylitol & -232.1687 & -51813.3577 & 2.6999005 & 1.598293 & -2.43693 & 3.972734 & 1 \\
Neotame & -219.7012 & -106698.2336 & -1.1188587 & 0.5262 & 3.658205 & 3.861502 & 10000 \\
Alitame & -179.1632 & -89787.3139 & -1.9678169 & 0.519272 & 1.721008 & 2.665298 & 2000 \\
\hline
\end{tabular}

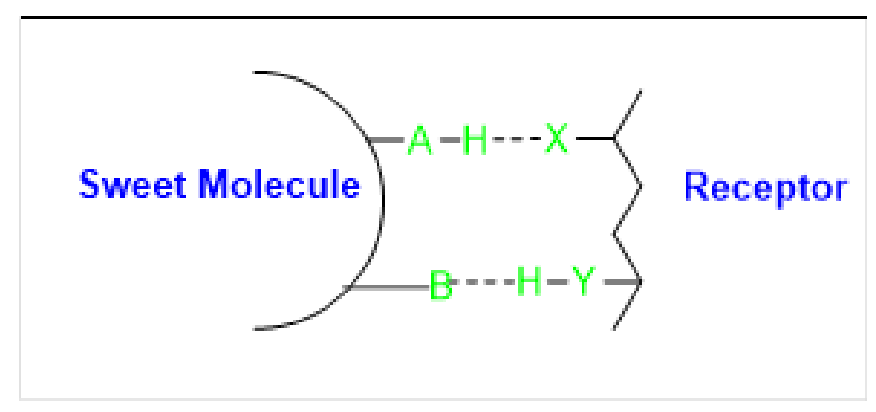

Figure 1: Interaction of the sweetener with the receptor site

To explain the relative sweetness of different sweeteners Lemont Kier proposed the B_X theory in 1972 (Kier, 1972). According to this theory, a compound must have a third site X, which is not an atom but is generally a region which usually does not bind to the receptor site. Generally, there are no direct evidences but it can be shown that hydrophobicity of the X region is directly related to the sweetness value (Kier, 1972; Gupta, 2010). 


\section{DISCUSSION}

\subsection{Aspartame}

The AH region in aspartame is likely to be present in a region of high electron density. From the ESP mapping (Table 4), the regions shown in red colors over $\mathrm{O}$ atoms are of high electron density and it is evident from the fact that oxygen has high electronegativity. Also, there is a hydrogen atom bonded to the oxygen atom, so this constitutes our $\mathrm{AH}$ region. B region is likely to be an electron rich region that can donate electrons to the $\mathrm{AH}$ region of the receptor site. Hence, it can be the $\mathrm{N}$ atom adjacent to it. The distance between the $\mathrm{AH}$ region and the B region was found to be $3.097 \AA$ which agrees well with the AH-B theory (Table 4).

Table 4: Electrostatic potential surfaces of artificial sweeteners

Artificial Sweetener


<smiles>OCC1O[C@@H](O[C@]2(CCl)O[C@H](CCl)[C@@H](O)[C@H]2O)[C@H](O)[C@@H](O)[C@H]1Cl</smiles>

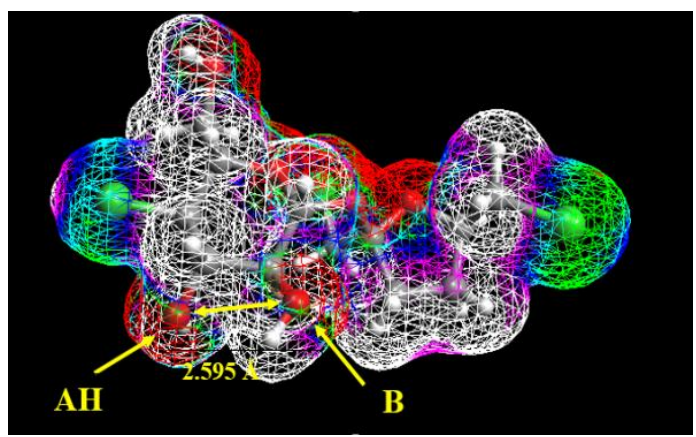

Cyclamate
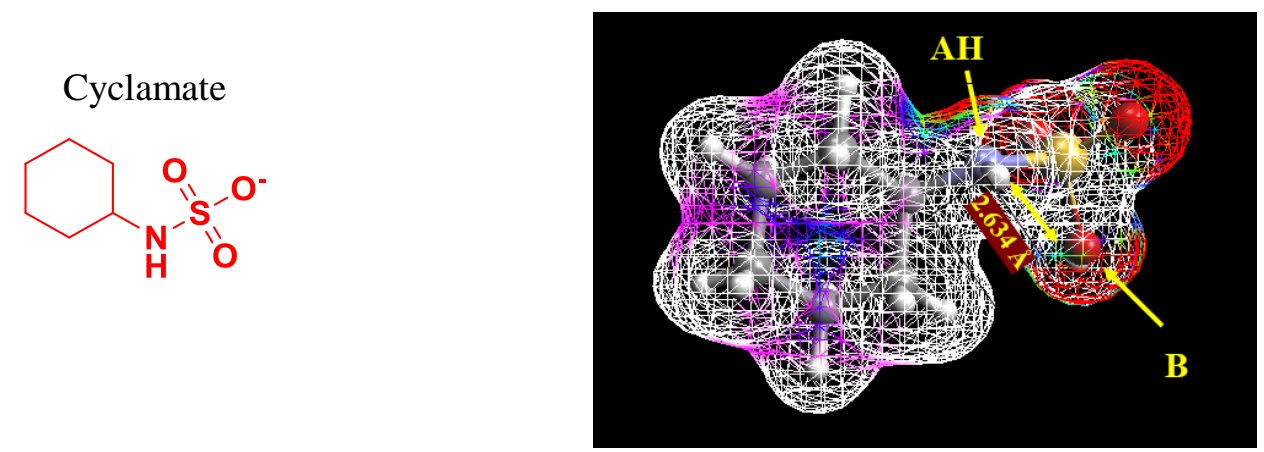

The $\mathrm{X}$ region is generally hydrophobic and usually contains a phenyl ring. It can be differentiated from the other regions of the molecule by the presence of HOMOs located on it (Table 2). However, no such relationship was found for the LUMOs.

\subsection{Xylitol}

In this molecule, there are five hydroxyl groups attached, around which the electron density is quite high. However, only two of them shown have the proper alignment and the requisite bond distance that is $2.648 \AA$ in accordance with the AH-B theory (Table 4). The rest of the part of the molecule is considered to be the $\mathrm{X}$ region but in case of xylitol it is not that bulky and doesn't contain a phenyl ring (Table 2) which accounts for the low relative sweetness value of xylitol.

\subsection{Sachharin}

In sachharin, although the maximum electron density is centered on the $\mathrm{O}$ atoms, but since, no hydrogen is bonded to $\mathrm{O}$ atoms therefore, it can't be considered as the $\mathrm{AH}$ region. The $\mathrm{AH}$ region can be the sp3 hybridised nitrogen atom which has the next highest electron density after oxygen. The electron rich B region can be any of the oxygen atoms bonded to sulphur atom (Table 4). The $\mathrm{X}$ group is the hydrophobic phenyl ring adjacent to the AH-B region where the maximum HOMOs are present (Table 2). 


\subsection{Sucralose}

In sucralose, the $\mathrm{AH}$ region is the hydroxyl group bonded to the six membered ring and the $\mathrm{B}$ region can be the sp3 hybridised oxygen atom adjacent to it (Table 4). The $\mathrm{X}$ group is the remaining part of the molecule, which in addition, also contains bulky $\mathrm{Cl}$ atoms (Table 2).

\subsection{Cyclamate}

The structure of cyclamate ion was drawn. However, the software Argus lab is not sensitive to negative charged species. Hence, in order to simplify, a hydrogen atom was attached to the negatively charged oxygen atom and the electrostatic potential mapped surface was generated. In cyclamate, the $\mathrm{AH}$ region can be the sp3 hybridised $\mathrm{N}$ atom and the $\mathrm{B}$ region can be any of the oxygen atom doubly bonded to the sulphur atom. $\mathrm{X}$ group is the remaining six-membered ring (Table 4).

According to the AH-B theory we have tried to identify the AH, B and $\mathrm{X}$ regions in different artificial sweeteners. An attempt has been made to extend this approach to establish a relationship between structure and relative sweetness values by comparing the hydrophobicity of the $\mathrm{X}$ group. The values of the relative sweetness of different artificial sweeteners have been listed in Table 3. In xylitol, there is no bulky $\mathrm{X}$ group present which agrees with the relative sweetness value that is one (01) with respect to sucrose. In cyclamate, one six membered ring is present whereas in aspartame there is a phenyl ring which is more hydrophobic as compared to the hexyl ring. This is in agreement with the fact that relative sweetness of aspartame is higher than that of cyclamate.

In case of sachharin there is one phenyl ring intact whereas in case of sucralose there is no phenyl ring but the hydrophobicity of $\mathrm{X}$ group is quite increased due to the presence of three (03) bulky chlorine atoms attached to it. Therefore, it can be shown that relative sweetness of sucralose is more than that of sachharin.

\section{CONCLUSION}

The molecular structures of various artificial sweeteners were assessed and their AH, B and $\mathrm{X}$ sites were identified. The relative sweetness values were found to be in accordance with AH-B-X theory. Sweeteners having bulky X group had higher value of relative sweetness as compared to those having a less bulky $\mathrm{X}$ group.

\section{CONFLICT OF INTEREST}

The authors declare no conflict of interest. 


\section{SOURCE OF FUNDING}

The authors are thankful to Maitreyi College, University of Delhi for funding this research project.

\section{ACKNOWLEDGEMENT}

The authors thank Maitreyi College, University of Delhi for providing the platform to conduct the research.

\section{REFERENCES}

Acree, T.E. Shallenberger, R.S. \& Ebeling, S. (1998). Thirty years of the AH-B Theory. Developments in Food and Science, 40, 1-13. https://doi.org/10.1016/S0167$\underline{4501(98) 80027-7}$

Bellisle, F. (2015). Intense Sweeteners, Appetite for the Sweet Taste, and Relationship to Weight Management. Current Obesity Reports, 4(1), 106-110. DOI: 10.1007/s13679-014-0133-8

Chattopadhyay, S., Raychaudhuri, U. \& Chakraborty, R. (2011). Artificial Sweeteners-a review. Journal of Food Science and Technology, 51(4), 611-621. doi: 10.1007/s13197-011-0571-1

Corti, A. (1999). Low Calorie Sweeteners, Present and Future. World Review of Nutrition and Dietetics, Basel, Karger, 85, 52-57. DOI: 10.1159/isbn.978-3-318-00483-0

Glória M.B.A. (2003). Aspartame. In Benjamin Caballero Paul Finglas Fidel Toldra, F. (2 $2^{\text {nd }}$ Edition), Encyclopedia of Food Sciences and Nutrition. (pp 332-337). London: Academic Press.

Gao, J. \& Thompson, M.A. (1999). Combined Quantum Mechanical and Molecular Mechanical methods (American Chemical Society ACS Symposium Series). ISBN-10: 0841235902

Guley, P. \& Uhing, J. Comparison of Relative Sweetness to Molecular Properties of Artificial and Natural Sweeteners. Retrieved from http://shodor.org/succeed1.0/compchem/projects/fallo0/sweeteners/index.html\#refs

Gupta R. (2010). To study the market dynamics of artificial sweeteners \&amp; arrive at a marketing plan for the launch of a brand of sucralose. Retrieved from http://52.172.27.147:8080/jspui/bitstream/123456789/570/1/Gupta\%20Rohit.pdf

Kier, L.B. (1972). A molecular theory of sweet taste. Journal of Pharmaceutical Sciences, 61(9), 1394-1397. https://doi.org/10.1002/jps.2600610910 
Lewars, E.G. (2011). Computational Chemistry, Introduction to the Theory \&amp; Applications of Molecular \&amp; Quantum Mechanics (2nd ed.) Springer Dordrecht Heidelberg London New York.

Masharani, U. \& German M.S. (2011). Pancreatic Hormones and Diabetes Mellitus. In M.S. Shoback, D.G., Gardner D. (9th ed.), Greenspan's basic and clinical endocrinology. (pp 605). New York: McGraw-Hill.

Maguire, A. \& Rugg-Gunn, A.J. (2003). Xylitol and caries prevention-is it a magic bullet? British Dental Journal, 194(8), 429-436. https://doi.org/10.1038/sj.bdj.4810022

Mortensen, A. (2006). Sweeteners permitted in the European Union: safety aspects. Scandinavian Journal of Food \& Nutrition Research, 50(3), 104-116. DOI:10.3402/fnr.v50i3.1588

Queneau, Y., Jarosz, S., Lewandowski, B. \& Fitremann J. (2007). Sucrose Chemistry and Applications of Sucrochemicals. Advances in Carbohydrate Chemistry and Biochemistry, 61, 217-292. https://doi.org/10.1016/S0065-2318(07)61005-1

Shapiro, J. \& Grutlag, D. (2004). FoldMiner: Structural motif discovery using an improved superposition algorithm. Protein Science, 13(1), 278-294. https://doi.org/10.1110/ps.03239404

Temussi, P.A. (2006). The history of sweet taste: Not exactly a piece of cake. Journal of Molecular Recognition, 19(3), 188-199. https://doi.org/10.1002/jmr.767

Weihrauch, M.R. \& Diehl, V. (2004). Artificial sweeteners-do they bear a carcinogenic risk? Annals of Oncology, 15(10), 1460-1465. https://doi.org/10.1093/annonc/mdh256

Walters, D.E., Orthoefer, F.T. \& DuBios, G.E. (1991). Sweeteners: Discovery, Molecular Design, and Chemoreception American Chemical Society ACS Symposium Series ISBN 13: 9780841219038.

How to cite this article: Chopra, H., Gaba, R., Chaudhary, A., Chugh, M. \& Rawat, K. (2020). Relationship between Molecular Structure and Relative Sweetness of Various Artificial Sweeteners. Vantage: Journal of Thematic Analysis, 1(1), 147-160.

DOI: https://doi.org/10.52253/vita.2020.v01i01.13

(C) The Author(s) 2020.

This work is licensed under a Creative Commons Attribution 4.0 International License which permits its use, distribution and reproduction in any medium, provided the original work is cited. 